\title{
Low Power CMOS Full AdDer Design with 12 TRANSISTORS
}

\author{
Manoj $\operatorname{Kumar}^{1}$, Sandeep K. Arya ${ }^{1}$, Sujata Pandey ${ }^{2}$ \\ ${ }^{1}$ Department of Electronics \& Communication Engineering \\ Guru Jambheshwar University of Science \& Technology, Hisar, India, \\ manojtaleja@yahoo.com, aryalsandeep@rediffmail.com \\ ${ }^{2}$ Amity University, Noida, India \\ spandeyeamity . edu
}

\begin{abstract}
In present work two new designs for single bit full adders have been presented using three transistors XOR gates. Adder having twelve transistors shows power consumption of $1274 \mu \mathrm{W}$ with maximum output delay of 0.2049ns. Power consumption and maximum output delay shows variation [1274 - 141.77] $\mu \mathrm{W}$ \& [0.2049 - 0.4167] ns with varying supply voltage from [3.3 - 1.8] V. Further, reverse body bias technique for power reduction has been applied to adder. Adder with reverse body bias shows power consumption variations of [1270 - 1067.60] $\mu \mathrm{W}$ with varying NMOS reverse bias from [0.0 to - 2.0] V. Delay of adder shows variations [0.2049 - 0.2316] $n s$ with reverse bias variation [0.0 to 2.0] $\mathrm{V}$. Simulations have been carried out at different supply voltage with increasing reverse biased applied to NMOS transistor and results shows improvements in power consumption of adder. A comparison with earlier reported circuits have been presented and proposed circuit's shows less power dissipation.
\end{abstract}

\section{KEYWORDS}

CMOS, Exclusive-OR (XOR), full adder, low power design and reverse body bias.

\section{INTRODUCTION}

With continuous increase in complexity and number of components on integrated circuits, power consumption of VLSI (very large scale integration) circuits is increasing at a rapid rate. The demand and popularity of hand held battery operated devices further added research efforts in the field of low power CMOS design. Large power consumption affects the circuit operation and reliability by increasing temperature of circuits. Packaging and cooling costs of VLSI system also goes up with increase in power consumptions. Three major source of power consumption exists in CMOS circuits: 1) switching power due to output transitions 2) short circuit power due to current between $\mathrm{V}_{\mathrm{DD}}$ and ground during switching 3) static power due to leakage and static currents. Full adders being core building blocks in different VLSI circuits like comparators, parity checkers, compressors. Performance of adder circuit highly affects the overall capability of the system. Improvement in performance of full adder in terms of power consumption, delay and other parameters will affect system capability as a whole.

Many logic styles have been used in past for designing the full adder circuits. Standard static CMOS full adder with pull up and pull-down networks used 28 transistors [1]. Complementary pass-transistor logic (CPL) with 32 transistors shows better driving capability but dissipates large power [2].Transmission gate CMOS adder (TGA) was based on transmission gates and used 20 transistors [3]. Main disadvantage of TGA was that it requires double transistors that of pass transistor logic for implementations same logic function. A transmission function full adder (TFA) was based on transmission function theory and used 16 transistors [4]. A full adder cell implemented with 14 transistor using XOR design and transmission gates [5]. Multiplexer based adder (MBA) used 12 transistors with elimination of direct path to power supply were reported [6]. Static energy recovery full (SERF) adder with 10 transistors with reduced power DOI:10.5121/ijitcs.2012.2602 
consumption at the cost of large delay had been presented [7]. Another design with 10 transistors full adder by using XOR/XNOR gates had been reported [8]. Performance analysis of different tree structured arithmetic circuits had been presented [9]. A hybrid CMOS logic style adder with 22 transistors had been reported [10]. A full adder using 22 transistors based on hybrid pass logic with output drive had been presented [11]. Full adder for embedded applications using three inputs XOR have been reported [12]. A 16 transistor full adder cell with $\mathrm{XOR} / \mathrm{XNOR}$, pass transistors and transmission gate have been reported [13]. Structured approach for implementation of single bit full adders using XOR/XNOR has been reported [14] as shown in figure 1 . With partitioning the full adder module into minor module, equations (1) and equations (2) can be written as

Sum $=H$ xor $C_{\text {in }}=H . C_{\text {in }}{ }^{\prime}+H^{\prime} C_{\text {in }}$

$\mathrm{C}_{\text {out }}=\mathrm{A} \cdot \mathrm{H}^{\prime}+\mathrm{C}_{\mathrm{in}} \cdot \mathrm{H}$

Where $\mathrm{H}$ is half sum (A xor B) and $\mathrm{H}^{\prime}$ is complement of $\mathrm{H}$.

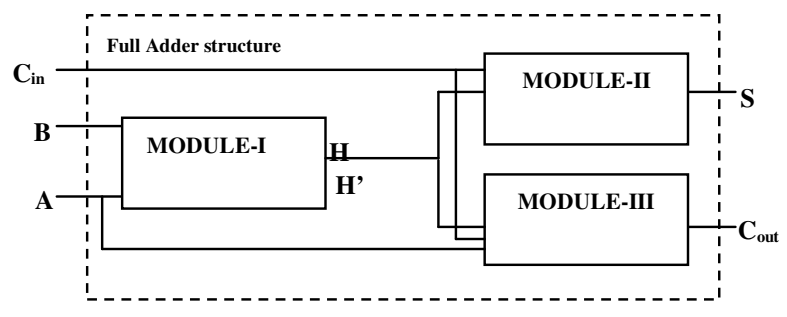

Figure 1. Structure of single bit full adder

To reduce the standby leakage in CMOS circuits, a reverse body biasing is generally used. Body biasing techniques make use of body terminal bias as another control mechanism to dynamically tune threshold voltages [16]. Threshold voltage $\left(\mathrm{V}_{\mathrm{th}}\right)$ is related by the square root of the bias voltage implying that a significant voltage level would be needed to raise the $V_{\text {th }}$. An optimized design is highly desirable at circuit level to avoid large power dissipation, large delay and to achieve sufficient output level. Here, an energy efficient single bit full adders with 12 transistors using three transistor XOR gate [15], inverters and multiplexer blocks have been presented., which shows better results in term of power dissipation. The paper is organized as follows: In Section II, new single bit full adders using 12 transistors have been reported. In section III results of power consumptions, maximum output delay results for the proposed full adder's cell have been presented and compared with earlier reported circuits. Conclusions have been drawn in Section IV.

\section{SYSTEM DESCRIPTION}

New single bit adders using three transistor XOR gate [15] and multiplexer blocks are presented in this paper. Sum and carry out $\left(\mathrm{C}_{\text {out }}\right)$ are generated by equations (1) and (2). Circuit diagram of first proposed adder (adder-I) with two XOR gates, two inverters and two multiplexers has been shown in figure 2. In Adder-I, $\mathrm{C}_{\text {out }}$ (carry out) signal has been generated by two transistor multiplexer block with $\mathrm{C}_{\mathrm{in}}$, A and XNOR signal. Sum signal is generated with XNOR signal generated by inverter and $\mathrm{C}_{\mathrm{in}}$ signal. Gate lengths of all transistors have been taken as $0.35 \mu \mathrm{m}$.

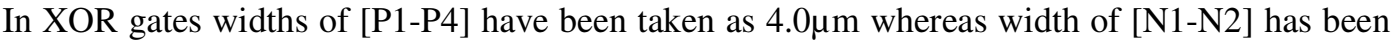
taken as $0.5 \mu \mathrm{m}$. Widths of all NMOS [N3-N6] have been taken as $1.0 \mu \mathrm{m}$ whereas widths of [P5-P7] have been taken as $2.5 \mu \mathrm{m}$. 


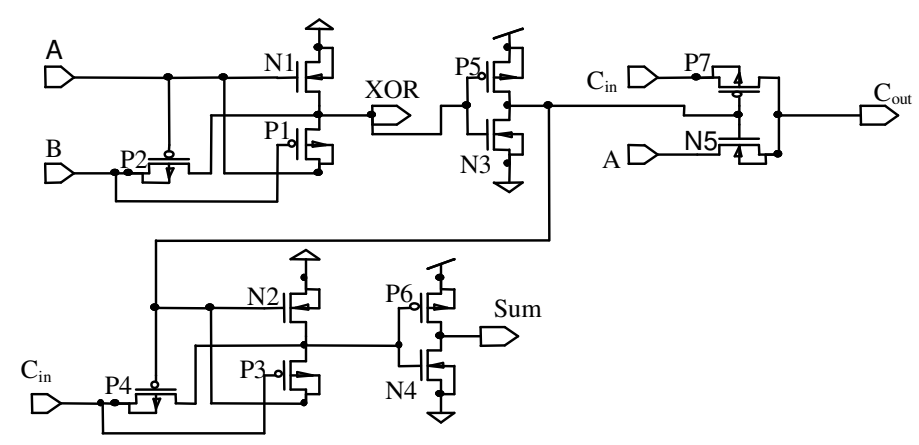

Figure 2. Adder-I with 12 transistors

A further improvement in above circuit has been made with reverse body bias. As CMOS inverter is responsible for major portion of power consumption in this adder circuit. Reverse bias voltage (V1) has been applied to two NMOS [N3 \& N4] used in CMOS inverters. Substrate terminal of PMOS [P5 \& P6] transistor used in inverter are connected to $\mathrm{V}_{\mathrm{DD}}$. By application of reverse body bias, the $V_{t}$ is increased as given in equation (3), which subsequently reduces the sub threshold leakage currents [16], [17].

$$
V_{t}=V_{t 0}+\gamma\left(\sqrt{2 \phi_{f}+V_{s b}}-\sqrt{2 \phi_{f}}\right)
$$

Where $V_{t 0}$ is threshold voltage for $V_{s b}=0 V ; \phi_{f}$ is Fermi potential and $\gamma$ is substrate bias coefficient.

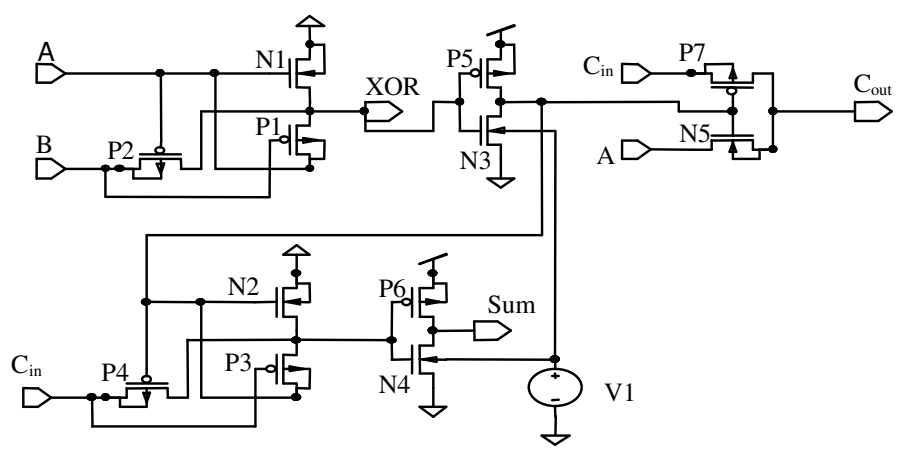

Figure 3. Adder-II with reverse body bias

\section{RESULTS AND DISCUSSIONS}

Simulations have been carried out in SPICE with TSMC $0.35 \mu \mathrm{m}$ process technology with supply voltage of $3.3 \mathrm{~V}$. Table-I shows results of power consumption and maximum output delay for adder with 12 transistors (adder-I) without reverse body bias. Supply voltage has been varied from [3.3 - 1.8] $\mathrm{V}$ and power consumption and maximum output delay results have been obtained. Figure 4 shows power consumption variation for the adder-I with varying supply voltage. Figure 5 show effects of supply voltage on maximum out put delay. Figure 6 shows input and output waveforms results for adder-I with supply voltage of 3.3V. 
International Journal of Information Technology Convergence and Services (IJITCS) Vol.2, No.6, December 2012

Table I. Power consumption and maximum out delay for adder-I

\begin{tabular}{|c|c|c|}
\hline $\begin{array}{l}\text { Supply } \\
\text { voltage } \\
\text { (V) }\end{array}$ & $\begin{array}{l}\text { Power consumption } \\
(\mu \mathrm{W})\end{array}$ & $\begin{array}{c}\text { Maximum output delay } \\
\text { (ns) }\end{array}$ \\
\hline 3.3 & 1274.0 & 0.2049 \\
\hline 3.0 & 957.009 & 0.2209 \\
\hline 2.7 & 685.141 & 0.2430 \\
\hline 2.4 & 457.826 & 0.2744 \\
\hline 2.1 & 274.315 & 0.3262 \\
\hline 1.8 & 141.776 & 0.4167 \\
\hline 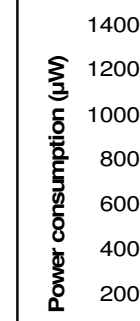 & & \\
\hline \multicolumn{3}{|c|}{ Supply voltage (V) } \\
\hline
\end{tabular}

Figure 4. Power consumption variations of adder-I with supply voltage

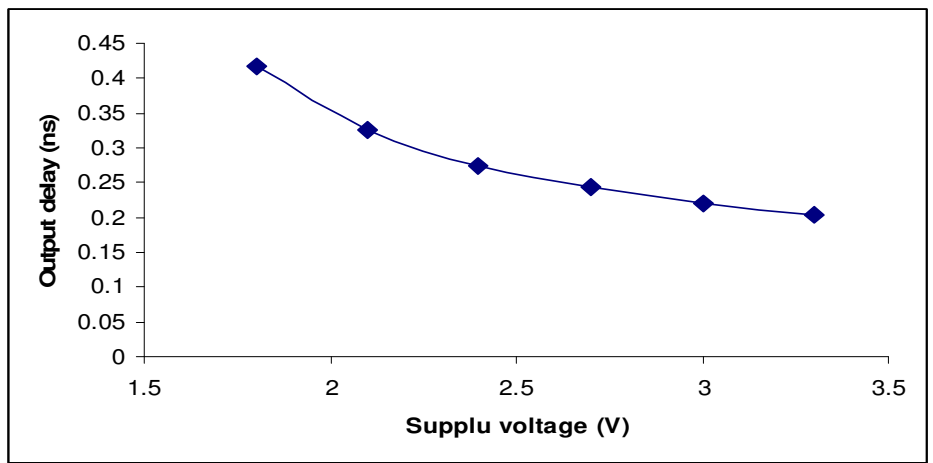

Figure 5. Output delay variations of adder-I with supply voltage 
International Journal of Information Technology Convergence and Services (IJITCS) Vol.2, No.6, December 2012

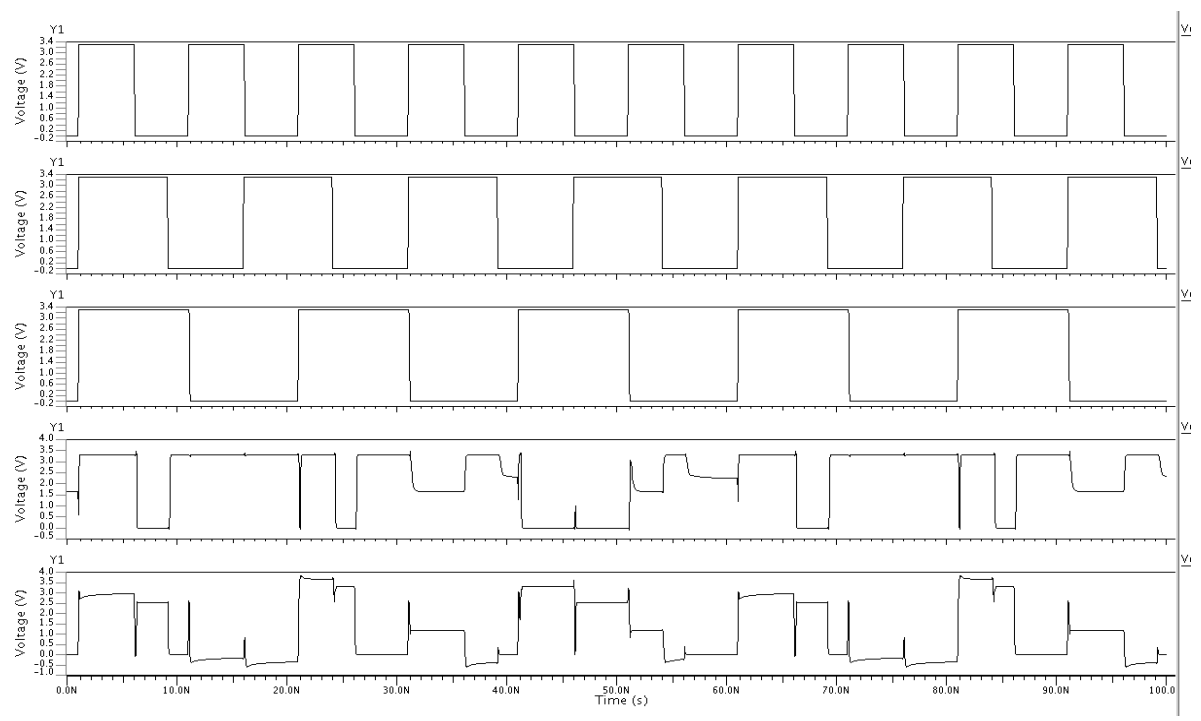

Figure 6. Input and out waveforms results for adder-I

Table-II shows the power consumption and delay results for adder (adder-II) with reverse body bias. Reverse body bias voltage has been varied from [0.0 to -2.0$] \mathrm{V}$ and power consumption and delay values have been obtained. Figure 7(a) \& (b) shows power consumption and delay variation with reverse bias voltage for adder-II at $3.3 \mathrm{~V}$ supply voltage.

Table II. Power consumption and delay with reverse bias for adder-II at $3.3 \mathrm{~V}$ supply voltage

\begin{tabular}{|c|c|c|}
\hline $\begin{array}{c}\text { Reverse body bias voltage } \\
(\mathbf{V})\end{array}$ & $\begin{array}{c}\text { Power consumption } \\
(\boldsymbol{\mu} \mathbf{W})\end{array}$ & $\begin{array}{c}\text { Maximum output delay } \\
(\mathbf{n s})\end{array}$ \\
\hline 0.0 & 1274.0 & 0.2049 \\
\hline-0.2 & 1252.0 & 0.2078 \\
\hline-0.4 & 1229.9 & 0.2105 \\
\hline-0.6 & 1207.9 & 0.2132 \\
\hline-0.8 & 1185.6 & 0.2159 \\
\hline-1.0 & 1164.4 & 0.2186 \\
\hline-1.2 & 1143.8 & 0.2213 \\
\hline-1.4 & 1123.9 & 0.2239 \\
\hline-1.6 & 1104.8 & 0.2265 \\
\hline-1.8 & 1086.4 & 0.2290 \\
\hline-2.0 & 1067.6 & 0.2316 \\
\hline
\end{tabular}




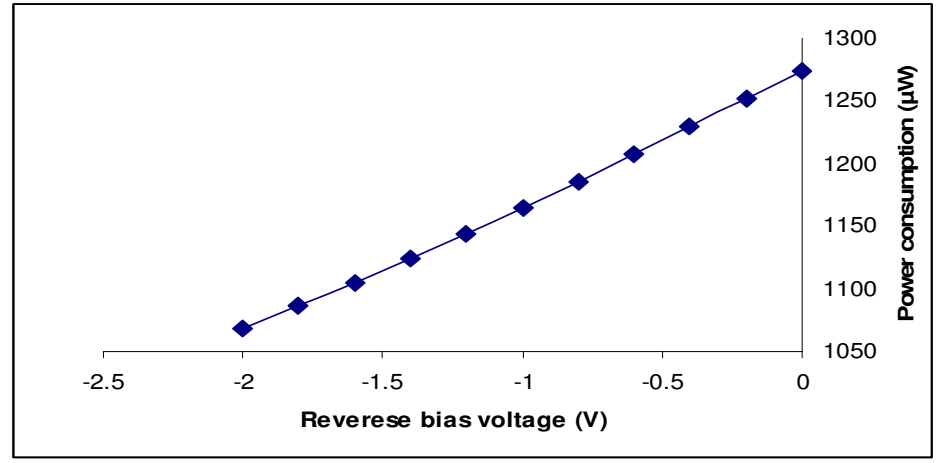

(a)

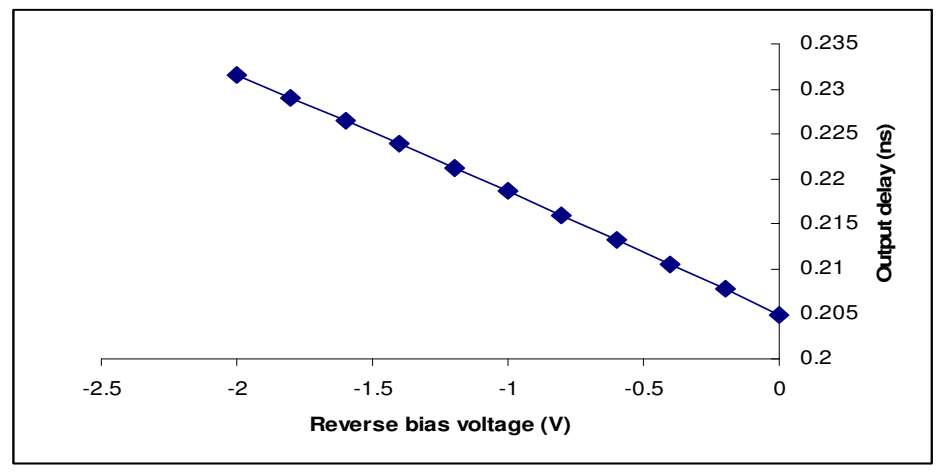

(b)

Figure 7. (a) Power consumption (b) delay variation for adder-II with reverse bias voltage

Figure 8 shows the power consumption variation for adder-II with different supply voltage and it has been observed that power consumption is reduced with increase in reverse bias voltage. Delay variation of adder-II (improved circuit of adder-I) also have been shown in figure 9 . Delay is slightly increased with increase in reverse body bias. Figure 10 shows input and out waveforms results for adder-II with reverse bias of $-1.0 \mathrm{~V}$ at supply voltage 0 f $3.3 \mathrm{~V}$. Some earlier reported circuits have been simulated in $0.18 \mu \mathrm{m}$ technology with same input parameters and input patterns as for proposed circuits. It has been observed from table IV that proposed circuit gives reduced power consumption with minimum transistors. 
International Journal of Information Technology Convergence and Services (IJITCS) Vol.2, No.6, December 2012

Table III. Power consumption and delay of adder-II at different supply voltages

\begin{tabular}{|c|c|c|c|c|c|c|c|c|}
\hline \multirow{2}{*}{$\begin{array}{l}\text { Bias } \\
\text { voltag } \\
\text { e }(V)\end{array}$} & \multicolumn{2}{|c|}{$\begin{array}{c}\text { Supply voltage }= \\
3.0 \mathrm{~V}\end{array}$} & \multicolumn{2}{|c|}{$\begin{array}{c}\text { Supply voltage }= \\
2.7 \mathrm{~V}\end{array}$} & \multicolumn{2}{|c|}{$\begin{array}{c}\text { Supply voltage }= \\
2.4 \mathrm{~V}\end{array}$} & \multicolumn{2}{|c|}{$\begin{array}{c}\text { Supply voltage }= \\
2.1 \mathrm{~V}\end{array}$} \\
\hline & $\begin{array}{c}\text { Power } \\
\text { consump } \\
\text { tion } \\
(\mu W)\end{array}$ & $\begin{array}{c}\text { Delay } \\
\text { (ns) }\end{array}$ & $\begin{array}{c}\text { Power } \\
\text { consump } \\
\text { tion } \\
(\mu \mathrm{W})\end{array}$ & $\begin{array}{c}\text { Dela } \\
\mathbf{y} \\
(\mathbf{n s})\end{array}$ & $\begin{array}{c}\text { Power } \\
\text { consump } \\
\text { tion } \\
(\mu W)\end{array}$ & $\begin{array}{c}\text { Delay } \\
(\mathbf{n s})\end{array}$ & $\begin{array}{c}\text { Power } \\
\text { consump } \\
\text { tion } \\
(\mu W)\end{array}$ & $\begin{array}{c}\text { Delay } \\
(\mathbf{n s})\end{array}$ \\
\hline-0.0 & 957.009 & $\begin{array}{c}0.220 \\
9\end{array}$ & 685.141 & $\begin{array}{c}0.24 \\
30\end{array}$ & 457.826 & 0.2744 & 274.315 & $\begin{array}{c}0.326 \\
2\end{array}$ \\
\hline-0.2 & 937.726 & $\begin{array}{c}0.224 \\
3\end{array}$ & 668.210 & $\begin{array}{c}0.24 \\
81\end{array}$ & 442.565 & 0.2801 & 261.489 & $\begin{array}{c}0.336 \\
8\end{array}$ \\
\hline-0.4 & 918.279 & $\begin{array}{c}0.227 \\
8\end{array}$ & 651.010 & $\begin{array}{c}0.25 \\
18\end{array}$ & 427.127 & 0.2876 & 251.134 & $\begin{array}{c}0.348 \\
6\end{array}$ \\
\hline-0.6 & 898.761 & $\begin{array}{c}0.231 \\
3\end{array}$ & 633.439 & $\begin{array}{c}0.25 \\
72\end{array}$ & 412.5072 & 0.2956 & 242.961 & $\begin{array}{c}0.362 \\
5\end{array}$ \\
\hline-0.8 & 879.134 & $\begin{array}{c}0.234 \\
7\end{array}$ & 616.593 & $\begin{array}{c}0.26 \\
13\end{array}$ & 399.6438 & 0.3027 & 236.919 & $\begin{array}{c}0.374 \\
9\end{array}$ \\
\hline-1.0 & 860.341 & $\begin{array}{c}0.238 \\
3\end{array}$ & 600.679 & $\begin{array}{c}0.26 \\
63\end{array}$ & 388.2397 & 0.3104 & 232.7321 & $\begin{array}{c}0.387 \\
7\end{array}$ \\
\hline-1.2 & 842.310 & $\begin{array}{c}0.242 \\
1\end{array}$ & 585.395 & $\begin{array}{c}0.27 \\
18\end{array}$ & 378.402 & 0.3185 & 230.006 & $\begin{array}{c}0.400 \\
7\end{array}$ \\
\hline-1.4 & 825.106 & $\begin{array}{c}0.245 \\
7\end{array}$ & 571.737 & $\begin{array}{c}0.27 \\
71\end{array}$ & 370.185 & 0.3261 & 228.325 & $\begin{array}{c}0.414 \\
0\end{array}$ \\
\hline-1.6 & 807.928 & $\begin{array}{c}0.249 \\
3\end{array}$ & 559.072 & $\begin{array}{c}0.28 \\
18\end{array}$ & 363.132 & 0.3341 & 227.328 & $\begin{array}{c}0.428 \\
5\end{array}$ \\
\hline-1.8 & 792.660 & $\begin{array}{c}0.252 \\
8\end{array}$ & 547.483 & $\begin{array}{c}0.28 \\
75\end{array}$ & 358.294 & 0.3413 & 226.751 & $\begin{array}{c}0.444 \\
1\end{array}$ \\
\hline-2.0 & 778.061 & $\begin{array}{c}0.255 \\
9\end{array}$ & 537.051 & $\begin{array}{c}0.29 \\
28\end{array}$ & 354.669 & 0.3530 & 226.417 & $\begin{array}{c}0.458 \\
6\end{array}$ \\
\hline & & $\begin{array}{l}\mathrm{Vdd}=3 \\
V \mathrm{Vdd}=2 \\
\mathrm{Vdd}=2 \\
\mathrm{Vdd}=2\end{array}$ & $\begin{array}{l}\square= \\
x \times x \\
x \times x\end{array}$ & bias ve & $\begin{array}{l}-1 \\
\text { age }(V)\end{array}$ & 0 & 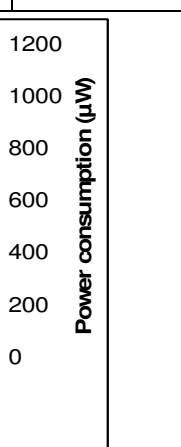 & \\
\hline
\end{tabular}

Figure 8. Power consumption with reverse body bias at different supply voltages 
International Journal of Information Technology Convergence and Services (IJITCS) Vol.2, No.6, December 2012

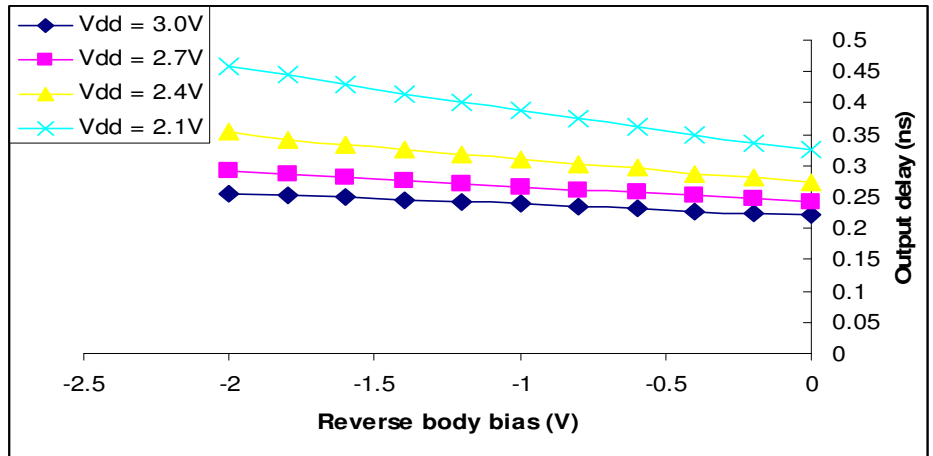

Figure 9. Output delay with reverse body bias at different supply voltages

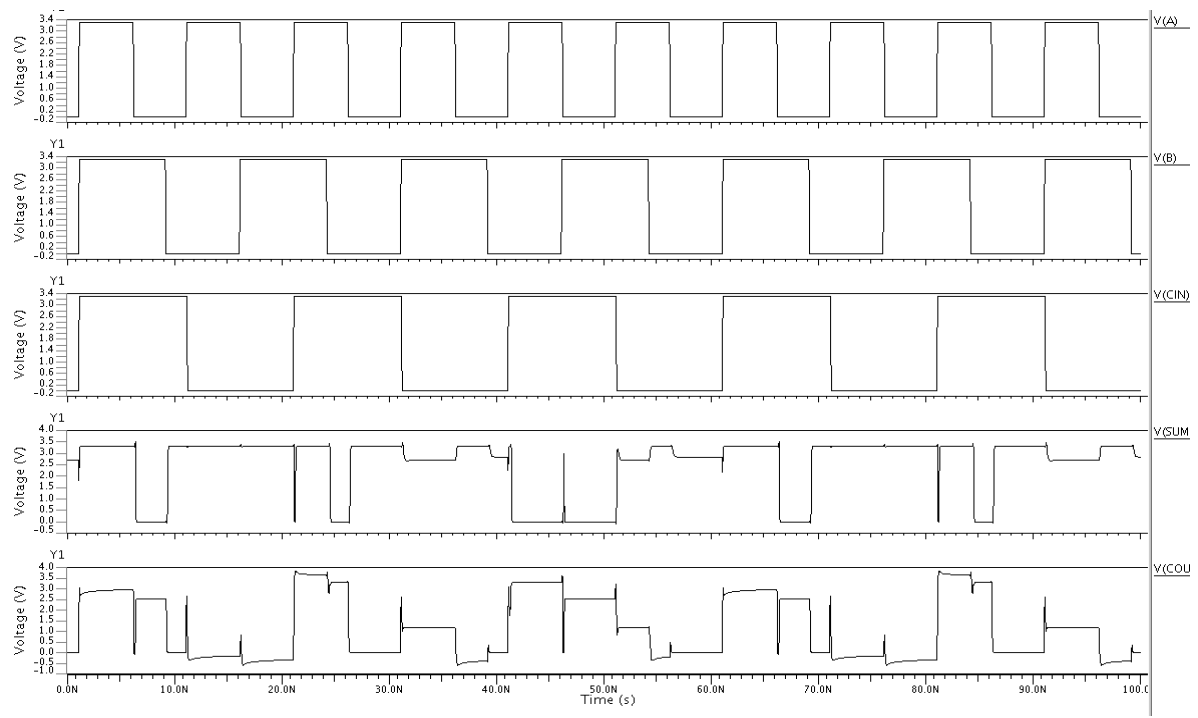

Figure 10. Input and output waveforms for adder-II with reverse bias of -1.0Vat 3.3V supply voltage

Table-IV. Comparison of power consumption with other circuits

\begin{tabular}{|c|c|l|}
\hline Adder configuration & Power consumption $(\boldsymbol{\mu W})$ & $\begin{array}{l}\text { Number of transistors for } \\
\text { design }\end{array}$ \\
\hline TGA20T [4] & 1255.54 & 20 \\
\hline 22T hybrid adder [7] & 1836.4 & 22 \\
\hline 22T HPSC [11] & 1533.9 & 22 \\
\hline 18T [3] & 617.23 & 18 \\
\hline Present work adder-I & 1274.0 & 12 \\
\hline Present work adder-II & 1067.6 & 12 \\
\hline
\end{tabular}


Power efficient adders have been designed with different combination of XOR and XNOR gates and pass transistor multiplexer concept. Power consumption has been reduced further with reverse body biasing of transistors. Reverse body biasing technique provides the way to reduce power consumption without adding any extra hardware on circuit. This work gives new design of single bit full adder with 12 transistors and extends the concept of body bias for optimized adder design. Results show that proper selection of bias voltage reduces the power consumption with little compromise in delay and contribute to overall performance of system.

\section{Conclusions}

In reported work two new circuits for single bit full adders have been reported. First circuit designed with 12 transistors shows power consumption of $1274.0 \mu \mathrm{W}$ with delay of $0.2049 \mathrm{~ns}$ at $3.3 \mathrm{~V}$ supply voltage. Adder circuit has been improved with reverse body bias technique and gives reduced power consumption. Adder-II shows power consumption variations [1274.0 1067.6] $\mu \mathrm{W}$ of with varying reverse bias voltage from [0.0 to -2.0] V. Delay of adder-II shows variation [0.2049 - 0.2316] ns with varying substrate bias from [0.0 to 2.0] V. Further, power consumption and delay results obtained with different supply voltage shows that power consumption has been improved in adder-II with slight increase in delay. Comparisons with earlier reported circuits show that proposed circuits shows lesser power consumption with reduced transistor count.

\section{REFERENCES}

[1] Y. Leblebici, S.M. Kang, CMOS Digital Integrated Circuits, Singapore: Mc Graw Hill, 2nd edition, 1999.

[2] R. Zimmermann, and W. Fichtner, "Low-power logic styles: CMOS versus pass-transistor logic," IEEE J. Solid State Circuits, vol. 32, no. 7, pp. 1079-1090, Jul. 1997.

[3] N. Weste and K. Eshraghian, "Principles of CMOS VLSI Design, A System Perspective," AddisonWesley, 1993.

[4] N. Zhuang and H. Wu, "A new design of the CMOS full adder," IEEE J. Solid-State Circuits, vol. 27, no. 5, pp. 840-844, May 1992.

[5] E.Adu-Shama and M.Bayoumi, "A new cell for low power adders," IEEE International Symposium on Circuits and systems, vol.4, pp.49-52, May, 1996.

[6] Yingtao Jiang Al-Sheraidah, A. Yuke Wang Sha, E. and Jin-Gyun Chung, "A novel multiplexer-based low-power full adder," IEEE Transactions on Circuits and Systems: Express Briefs, vol. 51, no. 7, pp.345-348, Jul. 2004.

[7] R. Shalem, E. John, and L. K. John, “A novel low-power energy recovery full adder cell,” IEEE Great Lakes Symposium on VLSI, pp. 380 - 383, March 1999.

[8] H. T. Bui, Y. Wang, and Y. Jiang, "Design and analysis of low-power 10-transistor full adders using XOR-XNOR gates," IEEE Trans. Circuits Systems II, Analog Digital Signal Process, vol. 49, no. 1, pp. 25-30, Jan. 2002.

[9] Chip-Hong Chang, Jiangmin Gu and Mingyan Zhang, "A review of $0.18 \mu \mathrm{m}$ full adder performances for tree structured arithmetic circuits," IEEE Transactions on Very Large Scale Integration (VLSI) Systems, vol.13,no.6,pp.686-695, Jun.2005.

[10] S. Goel. A. Kumar, M. A. Bayoumi, "Design of robust, energy efficient full adders for deep sub micrometer design using hybrid-CMOS logic style," IEEE Transactions on Very Large Scale Integration (VLSI) Systems, vol.14, no.12, pp.1309-1321, Dec. 2006.

[11] Zhang, M., J. Gu and C.H. Chang, "A novel hybrid pass logic with static CMOS output drive fulladder cell," IEEE International Symposium on Circuits Systems, vol. 5, pp. 317-320, May 2003. 
International Journal of Information Technology Convergence and Services (IJITCS) Vol.2, No.6, December 2012

[12] Chiou-Kou Tung, Yu-Cherng Hung, Shao-Hui Shieh, and Guo-Shing Huang, “ A Low-Power HighSpeed Hybrid CMOS Full Adder for Embedded System," IEEE conference on Design and Diagnostics of Electronic Circuits and Systems, pp.1-4, April, 2007.

[13] A. M. Shams and M. Bayoumi, "A novel high-performance CMOS1-bit full adder cell," IEEE Trans. Circuits System II, Analog Digital Signal Process, vol. 47, no. 5, pp. 478-481, May 2000.

[14] Ahmed M. Shams and Magdy A, "A structured approach for designing low power adders," ThirtyFirst Asilomar Conference on Signals, Systems \& Computers, vol. 1, pp.757-761, Nov. 1997.

[15] Manoj Kumar, Sandeep K. Arya and Sujata Pandey,” A new low power single bit full adder design with 14 transistors using novel 3 transistors XOR gate," IEEE international conference on computer modeling and simulation, vol.2, pp. 222-226,Jan.7-9, 2011.

[16] Keivan Navi, Omid Kavehie, Mahnoush Rouholamini, Amir Sahafi, and Shima Mehrabi, "A novel CMOS full adder," IEEE International Conference on VLSI Design, pp. 303-307, Jan. 2007.

[17] Dong Whee Kim, Jeong Beom Kim, "Low-power carry look-ahead adder with multi-threshold voltage CMOS technology," International Semiconductor Conference (CAS), vol.2, pp. 537-540, Sept. 2008.

[19] Keivan navi and Omid Kavehei, "Low-power and high-performance 1-bit CMOS full-adder cell," Journal of Computers, vol. 3, no. 2, pp. 48-54, Feb. 2008.

[20] Nima Taherinejad and Adib Abrishamifar, "A new high speed, low power adder; using hybrid analog-digital circuits," European Conference on circuit Theory and Design (ECCTD), pp. 623-626, Aug. 2009.

[21] Shiv Shankar Mishra, S. Wairya, R.K. Nagaria and S. Tiwari, "New design methodologies for high speed low power XOR-XNOR circuits," World Academy of Science, Engineering and Technology, vol.55, pp. 200-206, 2009.

[22] M.Hosseinghadiry, H. Mohammadi, M. Nadisenejani, "Two new low power high performance full adders with minimum gates," World Academy of Science, Engineering and Technology, vol. 52, pp. 10771084, 2009.

[23] Farshad Moradi, Dag.T. Wisland, Hamid Mahmoodi,Snorre Aunet,Tuan Vu Cao, Ali Peiravi, "Ultra low power full adder topologies," IEEE International Symposium on Circuits and Systems, pp. 3158 3161, May 2009.

[24] Dan Wang, Maofeng Yang, Wu Cheng, Xuguang Guan, Zhangming Zhu, Yintang Yang, "Novel low power full adder cells in 180nm CMOS technology," IEEE Conference on Industrial Electronics and Applications (ICIEA), pp. 430-433, May 2009.

[25] Chuen-Yau Chen and Yung-Pei Chou, "Novel low-power 1-bit full adder design," International Symposium on Communications and Information Technology, pp. 1348-1349, Sept. 2009.

[26] Reza Faghih Mirzaee, Mohammad Hossein Moaiyeri, Keivan Navi, "High speed np-CMOS and multi-output dynamic full adder cells," International Journal of Electrical and Electronics Engineering, vol. 4, pp. 304-310, 2010

[16] Adel S. Sedra and K. C. Smith, Microelectronics circuits, Oxford University press, New York, 1998.

[17] Kaushik Roy, Sharat C. Prasad, Low power CMOS circuit design, India: Wiely Pvt Ltd, Feb. 2002.

\section{Authors}

Dr. Manoj Kumar is working as assistant professor in Electronics \& Communication Engineering, Guru Jambheshwar University of Science \& Technology, Hisar, INDIA. He has published more than 15 research papers in international/national journals. His research interests include low power CMOS system, Integrated circuit designs and microelectronics. He is a Life Member of IETE (India), ISTE (India) and member of Semiconductor Society of India. 
Dr. Sandeep K. Arya is Professor and Head in the Department of Electronics \& Communication Engineering Department, Guru Jambheshwar University of Science \& Technology, Hisar, India. He received M. Tech. and Ph.D degree from NIT Kurukshetra. He has more than 17 years of experience in teaching and research. His current area of research includes Optical Communication System, Integrated circuit Fabrication and CMOS circuit design. He has published more fifteen papers in referred international/national journals. He has also published more than twenty research articles in national and international conferences.

Dr. Sujata Pandey received the Masters degree in electronics (VLSI) from Kurukshetra University in 1994 and the Ph.D degree from Department of Electronics, University of Delhi South Campus in Microelectronics in 1999. She is Professor in the Department of Electronics and Communication Engineering, Amity University, Nodia, INDIA. She has published more than 50 research papers in International/National Journals/ Conferences. Her current research interest includes modeling and characterization of HEMTs, SOI Devices, and low power CMOS integrated circuit design. She is member of IEEE and Electron Device society. 